\title{
MODIFICAÇÕES NO PROCESSO DE APRENDIZAGEM COM A INSERÇÃO DE TECNOLOGIAS DIGITAIS NA EDUCAÇÃO
}

Roniele Belusso*

Débora Peruchin**

Resumo: Os avanços nas tecnologias digitais modificam constantemente a sociedade e as relações culturais. A escola, inserida nessa realidade, precisa modificar suas práticas educacionais para acompanhar as novas necessidades e formas de ensinar e aprender. Com a inserção das tecnologias digitais em sala de aula, são modificadas as relações entre professor, alunos e objetos de conhecimento, podendo potencializar a aprendizagem. O presente estudo constitui-se de uma revisão bibliográfica a partir da seleção de três artigos científicos publicados em periódicos e inseridos na área de tecnologias digitais e educação. Utilizando a Análise Textual Discursiva, emergiram duas principais categorias para pensar o processo de aprendizagem com a inserção de tecnologias digitais: modificações nas relações coletivas e modificações na estrutura interna. Estas categorias abordam os tópicos: cooperação, ressignificação da realidade, autonomia e motivação. As tecnologias digitais, portanto, podem contribuir positivamente nos processos de ensino e aprendizagem, promovendo a cooperação entre os envolvidos, o entusiasmo e a atenção dos alunos e sua participação ativa na resolução de tarefas. Para isso, é necessário que o professor utilize as tecnologias digitais a favor do processo de aprendizagem, com criticidade e criatividade.

Palavras-chave: Tecnologias digitais. Aprendizagem. Educação.

\section{Introdução}

Com o advento das tecnologias digitais, novos modelos de conhecimento são construídos. Assim, Pierre Lévy (1999) convida a refletir sobre o novo espaço de comunicação no qual a sociedade está inserida, enfatizando as potencialidades deste em nível econômico, político, cultural e humano.

No lugar de uma representação em escalas lineares e paralelas, [...] a partir de agora devemos preferir a imagem de espaços de conhecimentos emergentes, abertos, contínuos, em fluxo, não lineares, se reorganizando de acordo com os objetivos ou os contextos, nos quais cada um ocupa uma posição singular e evolutiva (1999, p. 158).

Essa visão entende que, com a democratização do acesso à informação, os processos de pensamento, de construção do conhecimento e de visão da realidade contemplam novos

\footnotetext{
* Mestre em Educação pela Universidade de Caxias do Sul. Possui graduação em Farmácia pela Universidade Regional Integrada do Alto Uruguai e das Missões.

** Doutoranda em Educação na Universidade de Caxias do Sul. Possui Mestrado em Educação e graduação em Licenciatura em Matemática pela mesma universidade.
} 


\section{\#tear}

estilos de aprendizagem e fazem com que sejam questionados os modelos tradicionais de ensino, que enfatizam a transmissão dos saberes (LÉVY, 1999).

Este novo cenário incita a repensar os processos de aprendizagem e coloca possibilidades e provocações para as instituições - em especial, a escola. O professor, ao contrário de ser apenas fornecedor direto de informações para a construção do conhecimento, é incentivado a animar o intelecto de seus alunos incorporando e explorando novos recursos de aprendizagem, criando novos processos mais sintonizados com a atual realidade (LÉVY, 1999).

\footnotetext{
Não se trata aqui de usar as tecnologias a qualquer custo, mas sim de acompanhar consciente e deliberadamente uma mudança de civilização que questiona profundamente as formas institucionais, as mentalidades e a cultura dos sistemas educacionais tradicionais e sobretudo os papéis de professor e de aluno (LÉVY, 1999, p. 172, grifo do autor).
}

Esses questionamentos sobre como utilizar os recursos tecnológicos envolvem interfaces entre saberes, convivência e tecnologias digitais. O professor precisa, nesse contexto, organizar sua aula de modo que promova diálogo e cooperação, considerando o aluno em seu processo de construção de autonomia. É importante refletir sobre como a incorporação de tecnologias digitais pode incrementar as práticas educativas, redimensionando-as para que a inserção das tecnologias potencialize a inovação (SOARES; BRUSTOLIN, 2014).

Para que a incorporação de tecnologias digitais seja responsável por uma transformação no ambiente escolar, é necessário que comece por mudanças na cultura escolar. A mudança precisa acontecer na maneira como professor e alunos se relacionam "tanto entre si, como com o objeto de conhecimento, que nesse caso tem como elemento potencializador as tecnologias digitais e a capacidade dessas de ser meio de comunicação e de interação entre esses sujeitos" (SOARES; VALENTINI, 2012, p. 77).

Lévy compreende que o professor, neste contexto, é "incentivado a tornar-se um animador da inteligência coletiva de grupos de alunos" (1999, p. 158). Para Lévy (1999), cabe ao professor incentivar tanto a busca por conhecimentos como a mediação e a condução dos percursos de aprendizagem.

De maneira geral, os pesquisadores em educação buscam compreender o significado e as consequências da utilização de tecnologias digitais no ambiente escolar. Diversos estudos refletem sobre a necessidade de novas práticas pedagógicas, relacionando professor, aluno e conteúdo em um processo de comunicação que promova uma aprendizagem significativa. 
Neste contexto, estão inseridas as novas tecnologias da informação e comunicação (BUENO; ENS, 2016).

Desse ponto de vista, foi proposto investigar neste estudo a seguinte questão: Quais modificações ocorrem no processo de aprendizagem com a inserção de tecnologias digitais?

\section{Tecnologias digitais na educação}

A sociedade atual se destaca pela velocidade com que as informações circulam pelas redes de comunicações. O conhecimento é atualizado e reelaborado constantemente, fazendo com que teorias e estudos se tornem obsoletos num curto espaço de tempo (LÉVY, 1999). Mediante o cenário encontrado, cabe também à escola, enquanto formadora de cidadãos críticos, criar estratégias inovadoras utilizando as diversas ferramentas disponíveis, com o propósito de capacitar o aluno para resolver situações-problema nessa sociedade em mudanças.

As tecnologias digitais estão influenciando mudanças em todas as áreas. Informações que há anos demoravam para ser anunciadas, hoje podem ser disseminadas instantaneamente. No caso da escola, esse tipo de mudança oportuniza inovações no planejamento da prática educativa, em especial no diálogo pedagógico, refletindo na concepção de aprendizagem e no papel desempenhado pelo professor, que tem a possibilidade de

[...] redimensionar sua prática, criando ambientes de aprendizagem que possibilitem aos estudantes e a si mesmo interagirem e trabalharem juntos em problemas e projetos significativos. Isso pode contribuir para o desenvolvimento de habilidades necessárias para a formação de sujeitos capazes de relacionar-se com o contexto social contemporâneo, produzindo resultados significativos para o bem-estar social (SOARES; VALENTINI, 2012, p. 75).

Para que ocorra um espaço de aprendizagem, é necessário também que se forme um espaço de convivência responsável por interações constantes entre alunos e professor. A formação desse espaço de aprendizagem tem como um dos objetivos a reflexão sobre conteúdos teóricos específicos, fundamentados nas orientações e tarefas debatidas entre o professor e os alunos por meio de comentários, perguntas, respostas e sistematizações (SOARES; VALENTINI, 2012).

Aliada às tecnologias digitais, a aprendizagem deve ser considerada como um processo em que os alunos desenvolvem autonomia e criticidade, não podendo configurar-se apenas em transferência de informações (SOARES; BRUSTOLIN, 2014). As tecnologias da informação e comunicação (TICs) possibilitam uma transformação do sistema educativo, 
desde que haja o entendimento da necessidade de mudança no modelo de comunicação de um para muitos, buscando que o aluno assuma uma postura ativa na construção da sua aprendizagem. Assim, o professor deixa de ser considerado o detentor de todo conhecimento e passa a ser o orientador do processo de comunicação entre os envolvidos (LOPEZ; ÁVILA, 2015).

O conhecimento pode ser facilmente acessado por meio das novas tecnologias digitais. Assim, as TICs configuram-se como uma linguagem de comunicação essencial e consistem em um suporte ao desenvolvimento humano em dimensões de ordem pessoal, social e cultural. Mais do que um suporte, porém, as TICs devem ser um meio de promover a mudança e a criação de novas práticas de aprendizagem (ESTEVES, 2012).

As tecnologias digitais não podem ser ignoradas no contexto educacional, devendo ser vistas sob a possibilidade de promover transformações culturais, políticas, históricas, econômicas e sociais, com a construção de um ambiente colaborativo e que integra diferentes pontos de vista (LOPEZ; ÁVILA, 2015). Ao compreender a potencialidade educativa das tecnologias digitais, o professor pode utilizá-las para planejar suas atividades de maneira a proporcionar a aprendizagem de conteúdos e também o desenvolvimento da autonomia e da criatividade dos alunos (ESTEVES, 2012).

Soares e Brustolin (2014) enfatizam que a presença das tecnologias digitais na sociedade contemporânea faz emergir novas formas de ser e de conviver a partir do relacionamento entre os sujeitos, indo além de aspectos técnicos, pedagógicos e administrativos. Assim, pensar a cultura digital seria também pensar a cultura humana integrada à tecnologia digital, em um sistema vivo em que

[...] a convivência, ao promover o respeito mútuo, através da escuta dos anseios e receios dos professores, poderá permitir a aceitação do outro como legítimo outro em seu pensar, ao perceber a heterogeneidade que existe em uma sala de aula, tomando esses aspectos como promotores do enriquecimento e da inovação do processo de ensino e aprendizagem (SOARES; BRUSTOLIN, 2014, p. 658).

Com a rápida transformação da sociedade a partir das tecnologias de informação e comunicação, há um aumento constante na busca por conhecimento (GARCIA, 2013). Nesse contexto, a escola abre-se para novas relações com o saber, provocando mudanças substanciais no interior da instituição (RODRIGUES; MANCINI; ROSINI, 2010), em que cada vez mais os indivíduos têm a possibilidade de buscar "diferentes maneiras de entender, ensinar, produzir, gerenciar, armazenar, divulgar e modificar conteúdos" (GARCIA, 2013, p. 13). 
Segundo Boufleuer (2013), em épocas anteriores, em que o acesso ao saber era mais restrito, o professor justificava sua condição por ser portador de informações que os alunos desconheciam. Atualmente, porém, esse pretexto vem sofrendo modificações. Desse modo, além de sistematizar e apresentar saberes culturais, o professor também deve constituir-se como sujeito inserido na cultura, para promover o engajamento dos alunos no processo de aprendizagem.

Somente dessa forma, como uma espécie de testemunho vivo, o professor conseguirá atestar a importância da aprendizagem dos conteúdos curriculares junto a seus alunos. Nesse sentido ele deverá superar o que seria uma apresentação neutra ou desinteressada de sua matéria, como se ela fosse algo alheio a sua vida (BOUFLEUER, 2013, p. 406).

O objetivo da educação básica, segundo Boufleuer (2014), é proporcionar aprendizagens gerais para formar para a cidadania. O professor atua com a intenção de proporcionar que os alunos sejam cidadãos do tempo presente, podendo, assim, ser cidadãos do tempo futuro. Por meio da aprendizagem são construídas novas habilidades, modos de percepção e maneiras de situar-se em relação ao outro. Nas instituições educativas, portanto, há o aprimoramento do sujeito em sua relação com o mundo social e cultural.

Pescador, Valentini e Fagundes (2016) consideram que as tecnologias digitais devem ser inseridas nas escolas como suporte a uma prática docente inovadora, e não apenas como uma ferramenta a ser utilizada em um momento isolado do processo educativo. A inserção de laptops na sala de aula, por exemplo, modifica as relações entre professor, alunos e objetos de conhecimento, podendo potencializar a aprendizagem. Essa configuração incentiva a cooperação e considera que a aprendizagem é fruto de sociointerações.

Nesse sentido, o laptop deve estar em sala de aula juntamente com outros recursos de aprendizagem, como livros, jogos, mapas, maquetes e brinquedos (FAGUNDES, VALENTINI, SOARES, 2010). O ambiente de aprendizagem organiza-se com a integração dos recursos presentes, possibilitando que o aluno estabeleça relações em um espaço de convivência e aprendizagem. Torna-se necessário, portanto, reorganizar a sala de aula, fisicamente e quanto à dinâmica pedagógica (PESCADOR; VALENTINI; FAGUNDES, 2016).

Com a inserção de tecnologias digitais, é possível acessar fontes de informação além do professor. Os laptops representam uma oportunidade de redimensionar as práticas educativas e a cultura escolar, desde que considerados sob uma prática pedagógica de interação e cooperação, para que não sejam apenas um instrumento para transmissão de 
informações. Assim, "não basta distribuir equipamentos ou instalar laboratórios de informática sem um planejamento pedagógico efetivo e sem propiciar condições para que os professores possam vivenciar e pensar o uso das TD [tecnologias digitais]" (PESCADOR; VALENTINI; FAGUNDES, 2016, p. 664).

Nessa direção, Fagundes, Valentini e Soares (2010) afirmam que a internet deve ser entendida como uma rede de construção coletiva, de modo que seu conteúdo seja acessado de forma crítica e criteriosa. O professor, assim, deve ensinar o aluno a ressignificar os conteúdos acessados, promovendo o desenvolvimento da sua autonomia. Uma das bases da aprendizagem, portanto, está na interação, na relação do sujeito que aprende com os demais, com o mundo e com diferentes objetos de conhecimento.

Nesse contexto de acesso às tecnologias digitais, os jovens se constituem sujeitos por meio de práticas educativas que promovem o desenvolvimento da autonomia. Nessa perspectiva, é importante compreender os modos de pensar do aluno, para melhor orientá-lo em seu processo de aprender a aprender (PESCADOR; VALENTINI; FAGUNDES, 2016). Além disso, é necessário perceber o aluno em sua totalidade, incluindo suas vivências em tecnologia. A partir da compreensão do perfil cognitivo e das ações dos alunos emergentes da cultura digital, é possível planejar estratégias e intervenções pedagógicas que contemplem o uso de tecnologias de forma educativa (FAGUNDES; VALENTINI; SOARES, 2010).

A qualificação dos professores para o uso de tecnologias digitais em suas práticas pedagógicas deve superar o ensino específico de como utilizar essas ferramentas. Segundo Pescador, Valentini e Fagundes, "não basta prover professores e estudantes com laptops (ou outros dispositivos móveis, como tablets, smartphones, etc), pois a tecnologia por si só não provoca mudanças” (2016, p. 659). Assim, é necessária a emergência de uma nova cultura sobre o que é ser professor e como planejar a ação educativa aliada aos recursos tecnológicos, de modo que os professores se sintam inseridos na cultura digital (PESCADOR; VALENTINI; FAGUNDES, 2016).

Quando a inserção de tecnologias digitais é realizada com o objetivo de proporcionar o desenvolvimento dos alunos, são propiciados recursos para que eles explorem novas e diferentes possibilidades, incentivando e orientando-os a utilizar as tecnologias de maneira crítica e consciente (PESCADOR; VALENTINI; FAGUNDES, 2016). Dessa maneira, a aprendizagem será fruto de "cooperação e interação, desenvolvidas entre e com os estudantes, tendo-os como sujeitos ativos no processo, e não como receptores de informação" (FAGUNDES; VALENTINI; SOARES, 2010, p. 156). 
Nesse processo, a avaliação deve contemplar não apenas o desempenho, mas também o desenvolvimento do aluno, promovendo a produção de atividades com mais qualidade. Com isso, o aluno será incentivado a interagir e a ser autor - não apenas consumidor de conteúdos estáticos. Desse modo, a inserção de tecnologias digitais deve unir professores, alunos e sociedade, já que apenas a presença de computadores e outros recursos tecnológicos na escola não garante a melhoria da qualidade da educação. É preciso, mais do que a inserir as tecnologias digitais na escola, redimensionar a prática educativa e a cultura escolar para proporcionar ao aluno sua participação crítica e autônoma no mundo.

Cox (2008) apresenta, no livro "Informática na educação escolar", desafios e potencialidades do uso dos recursos de informática na prática educativa. Com a facilidade de consulta às informações disponibilizadas na internet, tornou-se possível acessar dados e conteúdos em grande velocidade, proporcionando a "troca de experiência entre remotos pesquisadores, estudantes e/ou curiosos, contribuindo sobremaneira com a integração social dos seres humanos" (COX, 2008, p. 40). A pesquisa inserida na prática educativa proporciona a construção de conhecimentos e o desenvolvimento do sujeito, utilizando os recursos tecnológicos como aliados no processo de formação da cidadania.

Dentre os requisitos para o uso das tecnologias digitais na escola, Cox (2008) destaca a qualificação dos professores e a importância de equipar a escola com os recursos tecnológicos necessários, paralelamente à adequação pedagógica. É preciso esclarecer que as tecnologias digitais complementam - não substituem - recursos como o quadro-negro, giz, livros e cadernos.

A informática e as tecnologias digitais não são boas ou más por si só, visto que dependem do uso que se faz delas (COX, 2008). Assim, o professor deve atualizar-se continuamente e conhecer as tecnologias disponíveis para não subutilizá-las ou supervalorizálas, além de ser criativo e ter "cumplicidade com o educando para estabelecer parcerias na busca por soluções e construções" (COX, 2008, p. 117). As tecnologias digitais precisam ser utilizadas de forma criteriosa e consciente, para que possam ser inseridas com sucesso nas práticas educacionais escolares.

\section{Materiais e métodos}

Este estudo constituiu-se de uma revisão bibliográfica, no qual realizou-se uma consulta a artigos científicos publicados em periódicos e selecionados aleatoriamente, sob dois critérios: que relacionassem os temas tecnologias digitais, educação e aprendizagem; e que tivessem sido publicados há menos de cinco anos. Foram selecionados três artigos 


\section{\#tear}

relacionados à questão norteadora deste estudo, abrangendo diferentes tecnologias digitais. Cada artigo se refere a, respectivamente: vídeos de Youtubers; softwares livres; e jogos digitais.

O primeiro artigo, "Escola, multiletramentos e tecnologias na aula de Língua Portuguesa: reflexões a partir de um projeto sobre Youtubers", apresenta um estudo realizado por Bulla e Silva (2017). Com o objetivo de trabalhar multiletramentos e tecnologias e considerando que a escola deve ser comprometida com a formação de cidadãos críticos, desenvolveu-se o projeto 'Youtubers: seguir ou deixar de seguir?'. A atividade envolveu uma turma do $9^{\circ}$ ano do Ensino Fundamental de uma escola pública de Porto Alegre, composta por 26 alunos com idades entre 14 e 16 anos.

Além de analisar gêneros do discurso oral, audiovisual e multimodal a partir de vídeos de Youtubers famosos na internet, também foram produzidos vídeos pelos alunos como se os mesmos fossem Youtubers, promovendo o desenvolvimento da oratória e da capacidade de argumentação. Com o envolvimento da turma na elaboração dos vídeos a partir do projeto, foi realizada uma reflexão sobre a mídia e o fenômeno Youtubers na sociedade contemporânea.

O segundo artigo analisado para este estudo intitula-se "O uso do Software Livre e a construção da aprendizagem colaborativa: limites e possibilidades do Programa Um Computador por Aluno". Com o objetivo de analisar o benefício do uso do software livre para o desenvolvimento da aprendizagem e da colaboratividade em rede no contexto do Programa UCA (Um Computador por Aluno), Melo e Carvalho (2013) realizaram uma pesquisa em duas escolas da rede pública de ensino. Foram investigadas as transformações no contexto escolar com a utilização de dois diferentes softwares livres: GeoGebra e GCompris.

O software GeoGebra foi utilizado nas aulas de Matemática de turmas do Ensino Médio. Este software permite a construção de pontos, vetores, segmentos, retas, secções cônicas e também funções que podem modificar-se dinamicamente. O software GCompris, diferentemente, compreende atividades para crianças entre dois e dez anos de idade. O trabalho foi realizado em uma turma do $2^{\circ}$ ano do Ensino Fundamental. Além da livre exploração do pacote de aplicativos GCompris, também foram sugeridas atividades pela professora, como tarefas em que eram selecionadas as letras que completavam as palavras apresentadas. Outra atividade proposta a partir do software GCompris foi o uso do programa TuxPaint, editor de imagens em que as crianças operam com o mouse (MELO; CARVALHO, 2013).

O terceiro artigo selecionado foi o de Cox e Bittencourt (2017), "Estudo bibliográfico sobre o processo de construção de jogos digitais: a necessidade de sinergia entre o educar e o 
divertir". Partindo do pressuposto de que os jogos digitais podem favorecer a aprendizagem, os autores defendem que os jogos podem ensinar de maneira divertida. Ou seja, podem ser simultaneamente uma ferramenta educativa e de entretenimento. A diversão, nesse caso, não deve ser a recompensa ou a motivação, e sim o meio pelo qual se aprende.

Cox e Bittencourt destacam a relevância cognitiva dos jogos digitais ao promoverem o desenvolvimento de habilidades importantes ao processo de aprendizagem, como "atenção, concentração, orientação espacial, resolução de problemas, tomada de decisões, trabalho colaborativo, criatividade e outros" (2017, p. 17). Além disso, estabelecem relações entre os conhecimentos necessários ao desenvolvimento de jogos de propósito geral e jogos de caráter educativo para construir, então, jogos que educam enquanto mantêm o caráter de diversão.

Para o processamento da informação contida nos textos, foi utilizada a Análise Textual Discursiva (MORAES; GALIAZZI, 2006). O processo de Análise Textual Discursiva consiste em criar condições para novas compreensões com base na interpretação dos textos a que se propõe examinar, constituindo assim, um conjunto de significados em função dos conhecimentos e teorias de que dispõe o pesquisador. Esta análise, enquanto mediadora na produção de significados, só pode ser obtida quando o leitor faz um movimento intenso de contato e impregnação com o material de análise (MORAES, 2003).

O processo de análise inicia com a unitarização ou desmontagem dos textos, que são fragmentados em unidades de significados. Após, é feita a categorização, na qual são agrupadas as unidades de significado semelhantes em categorias. Em sequência, há a construção de metatextos, em que ocorre a elaboração de textos descritivos e interpretativos com base nas categorias obtidas (MORAES, 2003; MORAES; GALIAZZI, 2006).

\section{Análise e resultados}

Nesse estudo, foram organizadas duas categorias: modificações nas relações coletivas e modificações na estrutura interna. Para cada categoria foram construídos alguns indicadores, levando em conta a problemática da pesquisa e os resultados encontrados nos artigos analisados.

\subsection{Modificações nas relações coletivas}

Esta categoria refere-se às relações interpessoais que são estabelecidas no grupo por meio do uso de tecnologias da informação. Corresponde às mudanças de hábitos e comportamentos nas formas de interação entre os indivíduos. Foi destacado como indicador: cooperação. 
A introdução das tecnologias da informação na educação está associada não apenas a mudanças tecnológicas, mas também sociais. É possível perceber que o uso de diferentes tecnologias possibilita a cooperação entre os alunos na realização de tarefas em sala de aula. Nesse contexto, a aprendizagem colaborativa considera que os alunos são sujeitos ativos na construção de conhecimento e promove um "trabalho coletivo em que o conhecimento ocorreria por meio de troca constante de informações, de pontos de vista, de questionamentos, de resoluções de questões e problemas" (ALONSO; VASCONCELOS, 2012, p. 61). Assim, há cooperação entre os envolvidos no processo educativo, integrando objetivos individuais e coletivos.

Alguns exemplos encontrados nos artigos selecionados são apresentados a seguir:

\begin{abstract}
Uma prática alternativa à entrega de uma tabela pronta para os alunos analisarem os vídeos seria a turma construir coletivamente os critérios de análise, tomando como base os elementos - identificados ao longo das leituras, discussões e análises de vídeos - constituintes do que seria um bom vídeo de Youtuber para a turma (BULLA; SILVA, 2017, p. 1994).
\end{abstract}

[No uso do software] o professor sistematizava o que fora aprendido a partir das informações descobertas pelos alunos que interagiam e participavam ativamente da aula, inclusive questionando se além das formulações trazidas pelo professor era possível outras formas de se chegar ao mesmo ou a outros resultados (MELO; CARVALHO, 2013, p. 6).

[O uso do software livre] promove a colaboração na medida em que os alunos com mais facilidade e habilidade auxiliavam os que possuíam mais dificuldades [...] Além disso, o trabalho exigiu uma mudança na conformação da sala de aula e uma mudança na relação professor-aluno, pois este interagia e se aproximava de cada aluno individualmente e em grupo, procurando ajudá-los em suas dificuldades (MELO; CARVALHO, 2013, p. 6).

A socialização, a cooperação, a criatividade, a interatividade e a interdisciplinaridade que caracterizam os jogos de RPG os tornam excelente ferramenta educacional (COX; BITTENCOURT, 2017, p. 32).

[Alguns jogos digitais] buscam garantir que os jogadores sejam capazes de se comunicarem uns com os outros através de sistema integrado de bate-papo; procuram estimular a colaboração pela proposição de tarefas solucionáveis apenas se os utilizadores agirem em grupo (COX; BITTENCOURT, 2017, p. 37).

\title{
4.2 Modificações na estrutura interna
}

A segunda categoria aborda modificações internas dos mecanismos cognitivos, em que o comportamento do indivíduo é influenciado e seu conhecimento adquire novas significações. Esta categoria destaca: a ressignificação da realidade, a autonomia e a motivação.

Quanto à ressignificação da realidade, o aluno pode atribuir um novo significado a determinados conceitos ou teorias por meio de diferentes contextos tecnológicos, 
possibilitando melhorar o grau de resolução diante de determinadas problemáticas.

Encontram-se a seguir alguns trechos que ressaltam esse indicador:

O projeto foi configurado [...] a partir de problematizações acerca dos motivos pelos quais certos Youtubers são populares ou não, sobre como os alunos se relacionam com essa cultura surgida no YouTube, sobre interlocução (posições de autoria e seleção de interlocutores) e propósitos dos vídeos, sobre estratégias de persuasão e sobre tensões entre cultura escrita-audiovisual e construção de 'verdades' (BULLA; SILVA, 2017, p. 1991).

Procuramos demonstrar de que maneiras um trabalho como o aqui analisado pode aproximar as experiências dos alunos com a escola, aproveitando as tecnologias, a internet e os gêneros do discurso existentes fora de sala de aula, a fim de fomentar novos modos de aprendizagem e promover a aproximação dos conteúdos escolares com outras esferas de atividade humana (BULLA; SILVA, 2017, p. 1995).

[O uso do software livre] se apresenta como um importante aliado do ensino e da aprendizagem, tanto na alfabetização de crianças quanto na materialização e transposição didática de conceitos abstratos da Matemática e ainda no desenvolvimento de múltiplas habilidades, além de modificar a organização do espaço pedagógico, a relação professor-aluno e ressignificar o currículo escolar ao articular os saberes escolares, os diferentes saberes trazidos pelos alunos e professores, aliado ao potencial das ferramentas tecnológicas (MELO; CARVALHO, 2013, p. 9).

O software livre GeoGebra transporta saberes abstratos (gráficos e funções) para a tela do computador, materializando conceitos que, em sua forma pura, aparentam $a$ priori uma desconexão com a realidade dos alunos e ao realizar esta transposição didática o conteúdo matemático torna-se mais significativo e interessante para alunos e professores (MELO; CARVALHO, 2013, p. 6).

[Na composição dos desafios] há [...] conhecimentos intrínsecos e extrínsecos - o intrínseco é obtido no contexto do jogo e o extrínseco é proveniente do mundo real (COX; BITTENCOURT, 2017, p. 25-26).

Jogos computacionais podem, de forma divertida e prazerosa, favorecer o ensino e a aprendizagem: desenvolvendo a atenção, a disciplina, a iniciativa, o autocontrole, o respeito a regras e habilidades perceptivas e motoras dos jogadores - indispensáveis no ato de jogar; estimulando o respeito mútuo, a solidariedade e a cooperação no cumprimento das tarefas em grupo; oportunizando, para o aluno, o uso da lógica, do raciocínio e de habilidades de organização para resolver problemas e superar desafios; bem como reforçando a autoestima dos seus usuários ao possibilitar que estes tenham bom desempenho, seja imediato ou conquistado gradualmente (COX; BITTENCOURT, 2017, p. 39).

O uso de tecnologias digitais mostra-se como uma ferramenta auxiliar na construção do conhecimento, o que possibilita uma ampla diversidade de caminhos e promove o desenvolvimento da autonomia. A autonomia do aluno é entendida como "a capacidade de buscar seus próprios meios e respostas a partir de um dado problema proposto pelo professor ou pela escola" (ABRUZZI, 2012, p. 30).

Os trechos destacados a seguir ilustram essas considerações: 
Ao abordar o videoclipe como gênero do discurso de estudo, a escola amplia não só as modalidades textuais, mas também a capacidade crítica de escolha e consumo dos alunos, tendo em vista que os gêneros multimodais são acessíveis e acessados a partir de diversos lugares e condições (BULLA; SILVA, 2017, p. 1990).

Ao promover a análise crítica das práticas de uso da linguagem e de produção de discursos no ciberespaço e na mídia, a escola pode se constituir como um espaço para a formação do cidadão que implica de modo informado e autoral na sociedade em rede contemporânea (BULLA; SILVA, 2017, p. 1995-1996).

O uso do software livre GeoGebra também levou os alunos a problematizarem questões e a pensarem em outras possibilidades a partir de suas descobertas (MELO; CARVALHO, 2013, p. 6).

Durante a investigação, os alunos buscavam também explorar outras atividades que nunca haviam realizado antes, sem nenhuma ajuda dos professores e sem a leitura prévia das regras do jogo que se encontram no menu de acesso da suíte de aplicativos. Os alunos demonstravam plena autonomia na interpretação das regras do jogo, ao acessar o menu inicial, selecionar atividades, descobrirem o objetivo destes e também aprendiam as regras com as experiências dos colegas (MELO; CARVALHO, 2013, p. 8).

Há ainda a forma de aplicar jogos na educação estimulando alunos a construírem seus próprios games. Uma iniciativa neste sentido é o Scratch que possibilita aos seus usuários criarem seus próprios jogos e animações, e os compartilharem com outros membros da comunidade on-line. A aprendizagem ocorre porque o aluno precisa efetuar pesquisas sobre o tema do jogo, idealizá-lo, aprender e aplicar recursos do Scratch, e sente motivação pelo produto obtido e pela apreciação de seus pares (COX; BITTENCOURT, 2017, p. 18).

[Jogos] de estratégia: games educacionais onde a tomada de decisões é indispensável para a formação autônoma, crítica e criativa; instigam decisões por parte do utilizador (COX; BITTENCOURT, 2017, p. 32).

Observou-se nos artigos analisados que a utilização das TICs para fins pedagógicos é um fator de motivação e também uma forma de inovação educativa. A motivação dos alunos é um importante desafio na educação, pois gera consequências na qualidade do envolvimento do aluno com o processo de ensino e aprendizagem. Ao estar motivado, o aluno busca oportunidades para a construção de novos conhecimentos, demonstrando entusiasmo e atenção, participando ativamente na resolução de tarefas e estando disposto a novos desafios (ALCARÁ, 2012).

Os trechos a seguir, destacados dos artigos selecionados, abordam aspectos relacionados à motivação:

A reportagem 'Quem são os youtubers mais famosos do Brasil e do mundo?' foi utilizada para promover uma discussão inicial sobre o fenômeno Youtubers, servindo de atividade de introdução temática e tentativa de mobilização e engajamento da turma com relação ao projeto. Após a leitura, os alunos foram convidados a compartilhar com os colegas quais celebridades da lista eles já conheciam e se tinham alguma identificação com elas. A resposta positiva da maioria dos alunos reforçou a necessidade do trabalho com o tema e evidenciou o interesse da turma (BULLA; SILVA, 2017, p. 1992). 
O seguinte comentário de uma das alunas evidencia ainda o caráter inovador do projeto: 'Eu gostei bastante! Achei super legal essa ideia de trazer assuntos novos e modernos para o ambiente escolar, tornando as aulas interessantes e divertidas pra todo mundo' (BULLA; SILVA, 2017, p. 1995).

[O uso do software livre] promove a colaboração na medida em que os alunos com mais facilidade e habilidade auxiliavam os que possuíam mais dificuldades, promovendo assim o aumento da autoestima dos alunos, pois ao realizarem a atividade com sucesso, todos exibiam animados as suas descobertas (MELO; CARVALHO, 2013, p. 6).

Durante a atividade os alunos participaram ativamente interagindo com as ferramentas e se revelaram encantados com a interface gráfica e com os recursos sonoros do programa (MELO; CARVALHO, 2013, p. 7).

Os softwares livres utilizados pelas escolas participantes do Projeto UCA se apresentam aos alunos como ferramentas interessantes no ambiente educacional, despertando-os para curiosidade e o interesse em buscar, criar e compartilhar conhecimento (MELO; CARVALHO, 2013, p. 8).

Um jogo digital educacional pode ser entendido como um software que tem bem definidos objetivos próprios de educação: motiva os alunos para os estudos, promove a aprendizagem; isto por meio de atividades de diversão, ou seja, prazerosas e desafiadoras (COX; BITTENCOURT, 2017, p. 17).

A familiaridade e a relação prazerosa existente entre aprendizes e games, aliada ao potencial educativo destes, justifica as iniciativas de aplicação de jogos como ferramentas educacionais (COX; BITTENCOURT, 2017, p. 20).

No processo de desenvolvimento de jogos digitais educacionais, havendo equilíbrio entre entretenimento e educação, o jogo não falha na motivação e na atração próprias de sua natureza divertida, bem como não subutiliza seu potencial educacional (COX; BITTENCOURT, 2017, p. 29).

Com motivação, o aluno deseja aprender, se aperfeiçoar, realizar descobertas e aprimorar suas capacidades. Além disso, como explicado, o uso de tecnologias digitais é favorável à educação também por promover a ressignificação da realidade e a autonomia dos alunos - modificações na estrutura interna -, além da cooperação entre os mesmos modificações nas relações coletivas. Observou-se, portanto, com a análise dos artigos selecionados, que a inserção de tecnologias digitais na educação promove modificações positivas no processo de aprendizagem.

Nesse sentido, é importante que o professor conheça os recursos tecnológicos disponíveis para melhor utilizá-los em suas aulas, adequando-os para que estejam a favor do ensino e da aprendizagem. É necessário, assim, ter criticidade e criatividade, promovendo a formação do aluno enquanto sujeito de sua própria aprendizagem e cidadão ativamente participante da sociedade. 


\section{Considerações finais}

Com a revisão bibliográfica realizada, confirmou-se que o uso de tecnologias digitais na educação é um recurso que auxilia no processo de ensino e aprendizagem, possibilitando diferentes experiências e novas formas de construção do conhecimento. A inserção de tecnologias digitais na prática educativa pode tornar o processo de aprendizagem mais interessante, interativo e motivador, por meio de modificações nas relações coletivas e na estrutura interna do sujeito.

Para serem utilizadas como uma ferramenta ou metodologia que apresenta inovação, as tecnologias digitais devem ser inseridas no contexto educacional de acordo com os objetivos da prática pedagógica, procurando potencializar a aprendizagem dos sujeitos envolvidos. Assim, novos ambientes de aprendizagem podem ser desenvolvidos em sala de aula, acompanhando recursos como giz e quadro-negro, para promover a construção e aplicação de conhecimentos.

Com a facilidade de acesso a diferentes recursos tecnológicos, a construção do conhecimento não deve ser pensada como algo que ocorre exclusivamente em sala de aula. As diversas informações obtidas no convívio social estão presentes na experiência pessoal dos alunos, que, com a mediação do professor, podem transformá-las em conhecimento formal. Para isso, é necessário que o professor não seja considerado detentor ou transmissor de conhecimentos, mas sim responsável por auxiliar o aluno - sujeito ativo de sua própria aprendizagem - a explorar e socializar os saberes, construindo conhecimentos.

As tecnologias de informação e comunicação, assim, colaboram para o aprimoramento do processo de ensino e aprendizagem, podendo ser utilizadas de forma a promover a interdisciplinaridade, com a integração de diferentes saberes. Além disso, podem ser desenvolvidas novas habilidades e novas relações entre professores e alunos, havendo uma reorganização do espaço educativo e configurando-o para promover a construção de conhecimentos.

No presente estudo, com a leitura e análise dos artigos selecionados, evidenciou-se a importância da inserção de tecnologias digitais na educação. Destacamos, assim, com as categorias que emergiram neste estudo, que o desenvolvimento de um processo de aprendizagem com a utilização de tecnologias digitais promove modificações nas relações coletivas, com a cooperação entre os envolvidos, e modificações na estrutura interna, promovendo, especialmente, a ressignificação da realidade, autonomia e motivação. A análise dos artigos selecionados ressaltou estes aspectos, mas sabe-se que diversas outras questões podem ser exploradas no contexto das tecnologias digitais na educação. 


\title{
MODIFICATIONS IN THE LEARNING PROCESS WITH THE INSERTION OF DIGITAL TECHNOLOGIES IN EDUCATION
}

\begin{abstract}
Advances in digital technologies constantly change the society and cultural relations. The school, inserted in this reality, needs to modify its educational practices to keep up with the new needs and ways of teaching and learning. With the insertion of digital technologies into the classroom, the relations between teachers, students and knowledge objects are modified, and this can enhance learning. This study is a bibliographical revision from the selection of three scientific articles published in periodicals and inserted in the area of digital technologies and education. Using the Discursive Textual Analysis, two main categories emerged to think about the learning process with the insertion of digital technologies: modifications in the collective relations and modifications in the internal structure. These categories address the topics: cooperation, resignificance of reality, autonomy and motivation. Therefore, digital technologies can contribute positively to the teaching and learning processes, promoting cooperation between those involved, the enthusiasm and attention of the students and their active participation in the task resolution. For this, it is necessary that the teacher uses the digital technologies in favor of the learning process, with criticality and creativity.
\end{abstract}

Keywords: Digital technologies. Learning. Education.

\section{Referências}

ABRUZZI, Leandro Gregis. O uso das TICs na educação: autonomia e conhecimento. 2012. 60 f. Trabalho de Conclusão de Curso (Ciências Sociais) - Universidade Federal do Rio Grande do Sul, Porto Alegre, 2012. Disponível em: <https://www.lume.ufrgs.br/bitstream/ handle/10183/66986/000871764.pdf>. Acesso em: 28 fev. 2018.

ALCARÁ, Adriana Rosecler. Compreensão de leitura, estratégias de aprendizagem e motivação em universitários: estudos de validade de medidas. 2012. 203 f. Tese (Doutorado em Psicologia) - Universidade São Francisco, Itatiba, SP, 2012. Disponível em: <http://www.usf.edu.br/galeria/getImage/427/604131434300132.pdf>. Acesso em: 01 mar. 2018.

ALONSO, Kátia Morosov; VASCONCELOS, Maria Auxiliadora Marques. As tecnologias da informação e comunicação e a aprendizagem colaborativa no ensino fundamental.

Contrapontos, v. 12, n. 1, p. 58-67, 2012.

BOUFLEUER, José Pedro. A escola que avalia e que é avaliada: educação e formação para a autonomia. Roteiro, Joaçaba, SC, v. 39, edição especial, p. 71-86, 2014.

BOUFLEUER, José Pedro. A profissão professor: crise de profissão ou profissão em crise? Linhas Críticas, Brasília, DF, v. 19, n. 39, p. 391-408, 2013. 
BUENO, Edina Dayane de Lara; ENS, Romilda Teodora. Tecnologia educacional: representação social de estudantes de Pedagogia. In: SIMPÓSIO ESTADUAL DE REPRESENTAÇÕES SOCIAIS E EDUCAÇÃO, 6., 2016, Salvador. Anais... Salvador: EDUNEB, 2016. p. 528-539.

BULLA, Gabriela da Silva; SILVA, Mariana Bulegon da. Escola, multiletramentos e tecnologias na aula de Língua Portuguesa: reflexões a partir de um projeto sobre Youtubers. Revista Ibero-Americana de Estudos em Educação, Araraquara, v. 12, n. 4, p. 1984-1997, 2017.

COX, Kenia Kodel. Informática na educação escolar. 2 ed. Campinas, SP: Autores Associados, 2008.

COX, Kenia Kodel; BITTENCOURT, Roberto Almeida. Estudo bibliográfico sobre o processo de construção de jogos digitais: a necessidade de sinergia entre o educar e o divertir. Revista Brasileira de Informática na Educação, v. 25, n. 1, p. 16-43, 2017.

ESTEVES, Bruno Alexandre Azevedo. A utilização do computador Magalhães na transformação das práticas educativas. 2012. 203 f. Dissertação (Mestrado em Tecnologias de Informação na Educação e Formação) - Instituto Politécnico de Bragança, Bragança, Portugal, 2012. Disponível em: <http://hdl.handle.net/10198/7627>. Acesso em: 28 fev. 2018.

FAGUNDES, Léa da Cruz; VALENTINI, Carla Beatriz; SOARES, Eliana Maria do Sacramento. Linguagem, educação e recursos midiáticos: quem mexeu na minha escola? In: PESCADOR, Cristina Maria; SOARES, Eliana Maria do Sacramento; NODARI, Paulo César (Orgs.) Ética, educação e tecnologia: pensando alternativas para os desafios da educação na atualidade. Curitiba: CRV, 2010. p. 143-158.

GARCIA, Tatiana Cristina Rodrigues. A escola na transição para o digital: desafios para a incorporação de TIC e a contribuição da TVD. 2013. 121 f. Dissertação (Mestrado em Televisão Digital) - Universidade Estadual Paulista, Bauru, 2013. Disponível em: <https://repositorio.unesp.br/bitstream/handle/11449/89560/garcia_tcr_me_bauru.pdf >. Acesso em: 28 fev. 2018.

LÉVY, Pierre. Cibercultura. São Paulo: Editora 34, 1999.

LOPEZ, André Porto Ancona; ÁVILA, Rodrigo Fortes. Blogs em Arquivologia: ferramentas de ensino-aprendizagem ou componentes do ato pedagógico? In: MATOS, Maria Teresa Navarro de Britto et al. (Org.). Perfil, evolução e perspectivas do ensino e da pesquisa em Arquivologia no Brasil. Salvador: EDUFBA, 2015. p. 133-149.

MELO, Rafaela da Silva; CARVALHO, Ana Beatriz Gomes Pimenta de. O uso do Software Livre e a construção da aprendizagem colaborativa: limites e possibilidades do Programa Um Computador Por Aluno. Novas Tecnologias na Educação, v. 11, n. 1, 2013.

MORAES, Roque. Uma tempestade de luz: a compreensão possibilitada pela análise textual discursiva. Ciência \& Educação, v. 9, n. 2, p. 191-211, 2003. 
MORAES, Roque; GALIAZZI, Maria do Carmo. Análise textual discursiva: processo reconstrutivo de múltiplas faces. Ciência \& Educação, v. 12, n. 1, p. 117-128, 2006.

PESCADOR, Cristina Maria; VALENTINI, Carla Beatris; FAGUNDES, Léa da Cruz. Laptops educacionais na modalidade 1:1: movimentos de inclusão digital em comunidades rurais. Revista de Educação Pública, Cuiabá, v. 25, n. 60, p. 657-677, 2016.

RODRIGUES, Mônica Cairrão; MANCINI, Mônica; ROSINI, Alessandro Marco. Innovation and knowledge management: reflections about knowledge and education. In:

INTERNATIONAL CONFERENCE ON INFORMATION SYSTEMS AND TECHNOLOGY MANAGEMENT, 7., 2010, São Paulo. Anais... São Paulo: CONTECSI, 2010. p. 1995-2013. Disponível em: <http://contecsi.fea.usp.br/envio/index.php/contecsi/ 7contecsi/paper/view/2239/1302>. Acesso em: 28 fev. 2018.

SOARES, Eliana Maria do Sacramento; BRUSTOLIN, Rosane Kohl. Convivência em contextos escolares permeados pela tecnologia digital: algumas considerações. In: SIMPÓSIO NACIONAL DE EDUCAÇÃO, 8., 2014, Frederico Westphalen. Anais... Frederico Westphalen, RS: URI, 2014. p. 648-659.

SOARES, Eliana Maria do Sacramento; VALENTINI, Carla Beatris. Tecnologias digitais: práticas e reflexões no contexto do ensino fundamental. Revista Linhas, Florianópolis, v. 13, n. 2, p. 74-88, 2012. 